\title{
Process and Development of Electrical Porcelain Insulator Using Edo State, Nigerian Raw Materials
}

\author{
Temitope Peter, Ologunwa \\ Industrial Design Department, Federal University of Technology, Akure, P.M.B 704, Ondo State, Nigeria
}

Received: 16 March 2020; Accepted: 25 March 2020; Published: 08 June 2020

\begin{abstract}
Ceramic products produced depend not only on the over-all chemical composition but also on the individual compositions, its crystalline structures and particles sizes of the raw materials. It has also been revealed that the appropriateness of particle size of materials used and the crystalline formation is much desired in the production of high strength electrical porcelain insulator. There is virtually no study conducted locally in Nigeria reviewed by the author at the point of compiling this study gave credence to particle sizes of materials as a considerable factor in producing their porcelain insulator. However, the dielectric and mechanical properties of the electrical porcelain insulators produced still need to be improved upon in order to produce high strength electrical porcelain insulators. The study therefore experiments by varying particle sizes $75 \mu \mathrm{m}$, $150 \mu \mathrm{m}$, and $300 \mu \mathrm{m}$ at developing electrical porcelain insulator with quality mechanical and dielectric strength using locally sourced raw materials. The raw materials were mixed by adopting two varied formulations from previous study, while slip cast techniques was employed in producing test samples sintered at $1200 \mathrm{oC}$ at the rate of 5 oC per minute. The physio-mechanical properties and dielectric strength of the samples were carried out in accordance to American Standard for Testing and Materials (ASTM) C20-00, and ATSM D116 standards. Sample A1S of $75 \mu \mathrm{m}$ particle size is the most acceptable of all the sample that met the required physio-mechanical and dielectric strength properties. However, this study suggests that $150 \mu \mathrm{m}$ particle sizes as a starting powder for production of electrical porcelain Insulator could also be used since its cost of processing is not much unlike $75 \mu \mathrm{m}$ particle size and could easily be achieved locally in Nigeria.
\end{abstract}

Index Terms: Ceramic Materials, Porcelain, Insulator, Particle size, Forming Technique.

(C) 2020 Published by MECS Publisher. Selection and/or peer review under responsibility of the Research Association of Mode rn Education and Computer Science

* Corresponding author.

E-mail address: 


\section{Introduction}

Insulator is one of the electrical safety components designed to curtail the flow of electrical charges in electric motor, appliances and devices that provide lights in the homes. The need to prevent dangerous effect of electricity flowing through a conductor requires a non- conductor such as insulators. An insulator contains no movable electric charges and when a voltage is passed through it, does not conduct electricity. It is extensively used in grid extension. The International Energy Agency (IEA) reported that more than 1 billion individuals stayed without access to power in 2014, of which the greater part were in India, Nigeria, Ethiopia, Democratic Republic of Congo and, Bangladesh[1].Without insulator, it is difficult for household, industries and all other power consumption outlets to connect to the national grid.

Insulator produced from ceramic materials is referred to as porcelain insulator. It is a vitrified fine grained ceramic whiteware body which can either be glazed or unglazed. It is composed basically of clay which gives plasticity to the mixture in order to make it workable; feldspar acts as fluxing agent at lowering the melting point of the mixture during heating and silica helps to maintain the shape of the formed article during firing. These three constituents that is clay, feldspar and silica, place electrical porcelain insulator in a phase system in term of oxide constituent when bisque - fired at 1200 oC [2,4].

According to Singer and Singer (1963), ceramic products produced depend not only on the over-all chemical composition but also on the individual compositions, its crystalline structures and particles sizes of the raw materials. It is also often influenced considerably by minor impurities which make it very difficult to make quantitative predictions about the optimum composition firing schedule for a desired product. It is also revealed in [3] that the appropriateness of particle size of materials used and the crystalline formation is much desired in the production of high strength electrical porcelain insulator. Asides [4,5], no other study reviewed by the author at the point of compiling this study gave credence to particle sizes of materials as a considerable factor in producing their porcelain insulator. It is noted in [6] that particle sizes affects fluidity, strength, plasticity, colour, abrasiveness and ease of dispersion of the kaolinite content suitable for production of porcelain insulator which is one of critical factors that can contribute to high strength of electrical porcelain.

The raw materials used to prepare porcelain bodies play a vital role in the ultimate product quality. It is an understatement to say that ceramic materials are not abundantly available in Nigeria. Studies reviewed show that there are abundant sources of materials for the production of electrical porcelain insulators in Nigeria. Some existing studies like [2, 3, 7] among others have exploited porcelain raw materials from various locations within Nigeria for the production of porcelain products. These studies have given insight to best materials locations and proved the abundance of such materials in Nigeria. Without evidence of doubt, this study agrees with other studies on mineral exploration in Nigeria that porcelain raw materials are readily available. Thus, locally available materials were optimally utilized in the course of this study with a view of providing source of information on available materials and its viability for prospecting porcelain insulator production industries with regard to local content maximization using locally available materials from Edo State, Nigeria.

To this end, this study investigates the effect of particle size, using slip casting techniques to produce electrical porcelain insulator with a good mechanical and electrical properties, with the objective of utilizing locally sourced materials from Edo State, Nigeria for production of porcelain insulator. Thus, assesses the quality of locally available ceramic raw materials in Edo state, Nigeria, and explores the effect of starting particle size of the materials that enhance the mechanical and electrical properties of electrical porcelain insulator.

\section{Summary of Related Literature}


The quest to improve the dielectric and mechanical strength of electrical porcelain produced locally was the major focus of this study. The production of ceramic products depends not only on the over-all chemical composition but also on the individual compositions, crystalline structures and particles sizes of the raw materials [8]. The material composition, crystalline structure, mode of production and particle size distribution have been considered in producing electrical Porcelain insulator due to their attributes in order to achieve desired dielectric and mechanical properties. Asides [5] and [3], no other study reviewed gave credence to particle sizes of materials as a considerable factor in producing their porcelain insulator. [7] noted that particle sizes affect fluidity, strength, plasticity, colour, abrasiveness and ease of dispersion of the kaolinite content suitable for production of porcelain insulator which is one of critical factors that can contribute to high strength of electrical porcelain.

Many studies have confirmed the abundance of raw materials in Nigeria. [9 - 12] gave the estimated deposit amount of ceramic raw materials that are available in Nigeria to be in millions of metrics tonnes. However, most of these raw materials are underutilized and the country is still much dependent on foreign electrical porcelain insulators among other ceramic products that can be produced locally. It is ironical that Ceramic products take the bulk share of imported goods in a country that is highly blessed with abundant raw materials that remain largely untapped. [13] remarked that if indigenous technology could be developed, it can boost the GDP of the nation through the utilization of these available local raw materials to produce standard electrical porcelain insulators both for local use and exportation. This study attempts to produce porcelain insulator of high dielectric and mechanical strength that could compete with imported insulators.

\section{Materials and Experimental Procedures}

\subsection{Raw Materials}

The materials sourced include: kaolin, feldspar, quartz and ball clay from Edo State in Nigeria. Feldspar and flint were sourced in Okpella while kaolin and ball clay were also sourced in Afowa both from Edo State, Nigeria. Sodium silicate which was used as deflocculating agent was purchased from Prime Standard and Chemical project Ltd, Igbesa road Ogun State, Nigeria; while the Plaster of Paris (P.O.P) for taking the mould was purchased in the market in Akure, Ondo State. Ball clay and Kaolin excavated were in lump form; this necessitated breaking the raw materials into smaller pieces before soaking using a sledge hammer in other to lessen the time taken for the materials to properly soaked before sieving the materials to remove impurities that were present.

The refined materials were further processed by using an Endecott test sieve shaker (Series number 11381) with set of Tyler sieves of British Standard to achieve $75 \mu \mathrm{m}, 150 \mu \mathrm{m}$, and $300 \mu \mathrm{m}$ particle sizes present in the material. The materials were sifted into three various particle sizes; Particle sizes that passed through sieve aperture $75 \mu \mathrm{m}$ were considered as $75 \mu \mathrm{m}$ particle sizes, while particle sizes that passed through $150 \mu \mathrm{m}$, and $300 \mu \mathrm{m}$ were considered as $150 \mu \mathrm{m}$, and $300 \mu \mathrm{m}$ particle sizes respectively.

\subsection{Sample Preparation}

Two different compositions were adopted from previous studies of [14] and [3] as shown in Table 1, while compositions were prepared in three varying particle sizes of $75 \mu \mathrm{m}, 150 \mu \mathrm{m}$, and $300 \mu \mathrm{m}$ in batches, in other to study the resultant effect on the mechanical and dielectric properties of porcelain insulator produced. Weighing balance was used in weighing the different batch compositions in respect to the particle size before it was formed using slip-cast technique. The detailed derivatives of porcelain insulator samples produced are shown in Table 2; six batch compositions were prepared, of which five replicates of each composition samples were produced and 30 samples were produced in all. 
Table 1. Adopted Sample Compositions

\begin{tabular}{cccccc}
\hline & $\begin{array}{c}\text { Kaolin } \\
(\%)\end{array}$ & $\begin{array}{c}\text { Clay } \\
(\%)\end{array}$ & $\begin{array}{c}\text { Feldspar } \\
(\%)\end{array}$ & $\begin{array}{c}\text { Quartz } \\
(\%)\end{array}$ & percentage \\
\hline $\begin{array}{c}\text { Composition A } \\
\text { [14] }\end{array}$ & 30 & 15 & 30 & 25 & 100 \\
$\begin{array}{c}\text { Composition B } \\
\text { [3] }\end{array}$ & 33 & 15 & 32 & 20 & 100 \\
\hline
\end{tabular}

Table 2. Detailed derivative of Porcelain Insulator samples Produced

\begin{tabular}{|c|c|c|c|}
\hline Particle sizes & $75 \mu \mathrm{m}$ & $150 \mu \mathrm{m}$ & $300 \mu \mathrm{m}$ \\
\hline Compositions & & & \\
\hline Composition A & $\mathrm{A}_{1} \mathrm{~S}$ & $\mathrm{~A}_{2} \mathrm{~S}$ & $\mathrm{~A}_{3} \mathrm{~S}$ \\
\hline Composition B & $\mathrm{B}_{1} \mathrm{~S}$ & $\mathrm{~B}_{2} \mathrm{~S}$ & $\mathrm{~B}_{3} \mathrm{~S}$ \\
\hline
\end{tabular}

*Note: $A$ = Olupot Porcelain Body Compositions

$B=$ Oladiji et.al. Porcelain Body Compositions

$1=75 \mu \mathrm{m} 2=150 \mu \mathrm{m} \quad 3=300 \mu \mathrm{m}$

$S=$ Slip cast (Solid) method

Polyvinyl plastic pipe which was dimensioned to $35 \mathrm{~mm} \times 25 \mathrm{~mm}$ was used as model and the mould was produced using Plaster of Paris (P.O.P). Five pieces of polyvinyl plastic pipe dimensioned to $35 \mathrm{~mm} \times 25 \mathrm{~mm}$ were set on a platform and a three-piece mould was produced for easy de-moulding of samples. The mould was further left to dry for 4weeks before it was being used for casting.

Samples produced were first dried in the oven for 2 hours at 200oC after they have been air dried for one week, before they were heat treated and sintered in a furnace (XD - 1700M) to $1200 \mathrm{oC}$ at the rate of 5 oC per minute, after which they were slowly cooled to room temperature to avoid thermal shock. Later, the physio-mechanical properties such as shrinkage, porosity, water absorption and density of the samples produced were analyzed according to American Standard for Testing and Materials (ASTM) C20-00 standard [15], the compressive strength of the fired samples were carried out using ASTM C-773 [16] ,while the dielectric test of the fired samples were also analyzed using ATSM D116 [17].

\section{Results and Discussion}

\subsection{Mineralogical Analysis of Raw Materials}

Table 3 shows the result of mineralogical analysis of the minerals that are present in the raw materials. The mineralogical analysis was conducted using X-Ray Diffraction to determine the mineral content in the raw materials used for the study. The result of the analysis in Table 3 showed that ball clay in the sample, contain $43.18 \%$ of quartz, $53.11 \%$ kaolinite, $0.77 \%$ Anatse and $2.94 \%$ of muscovite. Anatse present in the clay content is negligible, thus it does not have any significant effect on the samples while muscovite present though inappreciable in quantity, acts as a fluxing agent which helps at lowering the firing temperature during sintering[18].

The raw kaolin material used as presented showed that quartz had 21.99\%, Kaolinite 75.35\%, Anatse 
$0.87 \%$, Dolomite $1.26 \%$, and $0.52 \%$ of Calcite. The result showed that the raw kaolin had appreciable quantity of kaolinite which is more suitable for the formation of mullite [19] that is needed to improve the strength of an electrical porcelain insulator the quantity of quartz present indicate the chemical formula of kaolin which is Al2O3. 2SiO2 showing that alumina and silica are the basic constituents in kaolin.

Moreso, the XRD revealed that the raw silica material used to produce the porcelain sample contained $95.29 \%$ of quartz and $4.71 \%$ of kaolinite. The amount of quartz mineral present in raw silica proved the purity of the material; while the result established that the raw feldspar used for the composition contained $41.71 \%$ of quartz, $20.35 \%$ of albite, $32.72 \%$ of microcline, $4.67 \%$ biotite and $0.55 \%$ of calcite. The result also implied that the source of the feldspar is of good quality and suitable for ceramic production.

Thus, the result from the XRD conducted showed high level of purity of the silica content present in the materials. The ball clay and kaolin also showed good quality of aluminosilicate materials which is essential for mullite formation, while feldspar showed high concentration of potash feldspar which is a good fluxing agent that aid low eutectics. In all, the result proved the source of materials from Afowa and Okpella to be suitable for production of porcelain insulator.

Table 3. Mineralogical Composition of Raw Materials (XRD)

\begin{tabular}{|c|c|c|c|c|}
\hline $\begin{array}{c}\text { Mineralogical } \\
\text { Compositions (Wt. \%) }\end{array}$ & Clay & Kaolin & Silica & Feldspar \\
\hline Quartz & 43.18 & 21.99 & 95.29 & 41.71 \\
\hline Kaolinite & 53.11 & 75.35 & 4.71 & - \\
\hline Anatse & 0.77 & 0.87 & - & - \\
\hline Muscovite & 2.94 & - & - & - \\
\hline Dolomite & - & 1.26 & - & - \\
\hline Calcite & - & 0.52 & - & 0.55 \\
\hline Albite & - & - & - & 20.35 \\
\hline Microcline & - & - & - & 32.72 \\
\hline Biotite & - & - & - & 4.67 \\
\hline Calcite & - & - & - & 0.55 \\
\hline Total & 100 & 99.99 & 100 & 100.55 \\
\hline
\end{tabular}

\subsection{Determination of the Physio-Mechanical and Dielectric Property of Fired Samples Produced.}

\section{a. Physio-Mechanical Property}

In this study, the effect of starting powder of the material used on mechanical and electrical properties of electrical porcelain insulator bodies was determined. The physio-mechanical properties of the fired samples A1S, A2S, A3S, B1S, B2S, and B3S, sintered at 1200oC are shown in Table 4.

i. Linear Shrinkage (L.S \%): The linear shrinkage of the compositions in terms of length, diameter, and weight of samples before and after firing are as shown in Table 4 in accordance to ASTM C20-00 standard. Since the particle size and water content are closely related to the rate of permittivity as well as the loss tangent of composite [20], shrinkage value is considered and the result revealed that all the samples gave low shrinkage values which are suitable for insulator. The shrinkage level can be associated with the low quantity of non-plastic content in the raw materials. Also, the varying shrinkage value can be attributed to the particle size since porosity and particle sizes in the starting state is essential to the sintering properties of fine powders [21] and thus reduces the firing shrinkage.

ii. Apparent porosity (A.P \%): The apparent porosity of the compositions of the insulator samples produced at $1200^{\circ} \mathrm{C}$, revealed that sample $\mathrm{A}_{2} \mathrm{~S}$ has the lowest apparent porosity value (26.93\%), followed by sample $\mathrm{B}_{1} \mathrm{~S}$ 
and $\mathrm{B}_{2} \mathrm{~S}$ have apparent porosity of $30.40 \%$ and $34.70 \%$ respectively. Invariably, all compositions had high porosity value, and are still within range since apparent porosity and water absorption decrease with increase in firing temperature [22]. The more the firing temperature, the lower the apparent porosity and water absorption since high temperature results in liquid or glass phase which eventually fill up the void, thereby leading to densification of the insulator. In as much as apparent porosity and water absorption are directly proportional to each other, the result of the water absorption also estimated high. The results as presented in Table 4 also figured that sample $\mathrm{A}_{2} \mathrm{~S}$ has the lowest water absorption value (11.16\%), followed by samples $\mathrm{B}_{3} \mathrm{~S}$ and $\mathrm{A}_{1} \mathrm{~S}$ with $12.90 \%$ and $14.08 \%$ respectively. However, Sample $A_{3} S$ had the highest absorption rate of $16.56 \%$, while samples $\mathrm{B}_{1} \mathrm{~S}$ and $\mathrm{B}_{2} \mathrm{~S}$ ranked second and third in highest rate of absorption with $15.88 \%$ and $14.79 \%$ respectively. All the samples gave desirable water absorption values when compared with apparent porosity of fired refractory body since the insulator samples produced were unglazed.

iii. Bulk Density (B.D g/cm3) the result of the bulk density of the insulator samples compositions revealed that sample B1S has the lowest bulk density value $(1.9 \mathrm{~g} / \mathrm{cm} 3)$. Samples B2S and A2S also had low density values of $2.35 \mathrm{~g} / \mathrm{cm} 3$ and $2.41 \mathrm{~g} / \mathrm{cm} 3$ respectively. Sample B3S had the highest density of $3.04 \mathrm{~g} / \mathrm{cm} 3$, while sample A1S rated second highest value of $2.66 \mathrm{~g} / \mathrm{cm} 3$. However, the bulk densities of all the samples produced are in the close range and are within the tolerable value for porcelain insulator compare with [23] since increase in temperature brings about decrease in bulk density.

iv. Compressive Strength (C.S kN): The minimum failing load or combined electro mechanical strength according to technical specification for porcelain insulator (specification number D-24) as revised in 2001 for LT shackle insulator is $15-16 \mathrm{kN}$. The result in Table 4 revealed that only sample A1S met the required specification with compressive strength value of $25.67 \mathrm{kN}$ while others are below the recommended value. The compressive strength of the samples produced decreases as the particle size increases. This implies that agglomeration of smaller particle size is much more coherent than larger particle sizes, and thus improve the compressive strength of the sample.

Table 4: Change in Linear shrinkage (L.S \%), Apparent Porosity (A.P \%), Water Absorption (W.A \%), Bulk Density (B.D g/cm³), Compressive Strength (C.S kN), with the samples' compositions sintered at $1200^{\circ} \mathrm{C}$

\begin{tabular}{|c|c|c|c|c|c|c|}
\hline & $\mathrm{A}_{1} \mathrm{~S}$ & $\mathrm{~A}_{2} \mathrm{~S}$ & $\mathrm{~A}_{3} \mathrm{~S}$ & $\mathrm{~B}_{1} \mathrm{~S}$ & $\mathrm{~B}_{2} \mathrm{~S}$ & $\mathbf{B}_{3} \mathrm{~S}$ \\
\hline L.S (\%) & 2.00 & 1.36 & 0.98 & 1.04 & 1.64 & 2.48 \\
\hline A.P (\%) & 37.28 & 26.93 & 42.34 & 30.40 & 34.77 & 39.23 \\
\hline W.A (\%) & 14.08 & 11.16 & 16.56 & 15.88 & 14.79 & 12.90 \\
\hline B.D $\left(\mathrm{g} / \mathrm{cm}^{3}\right)$ & 2.66 & 2.41 & 2.56 & 1.91 & 2.35 & 3.04 \\
\hline C.S (kN) & 25.67 & 13.15 & 7.80 & 11.80 & 7.07 & 10.97 \\
\hline
\end{tabular}

\section{b. Dielectric Property}

i. Insulation Resistance (I.R G $\Omega$ ): The estimated value from the test for insulation resistance of the porcelain insulator samples produced as shown in Table 5 indicated that sample $\mathrm{B}_{2} \mathrm{~S}$ had the highest insulation volume resistivity of $1.84 \mathrm{G} \Omega$ at the injection of 1000 volts, sample $\mathrm{B}_{3} \mathrm{~S}$ had $1.74 \mathrm{G} \Omega$, and sample $\mathrm{A}_{1} \mathrm{~S}$ had $1.76 \mathrm{G} \Omega$. Sample $B_{1} S$ had the least resistivity of $1.16 \mathrm{G} \Omega$. Although, samples $B_{2} S$ and $B_{3} S$ had good insulation resistance, but are having low mechanical strength. The poor mechanical strength can be attributed to crack 
and flaws during composition of the samples [24]. Considering the fact that the mechanical strength and insulating properties are very germane to porcelain insulator, sample $\mathrm{A}_{1} \mathrm{~S}$ is much acceptable in as much that it satisfied both required properties of porcelain insulator as quoted in [24] that the minimum insulation resistance of $500 \mathrm{Meg}$ ohm at the injection of 1000Dc voltage is recommended by International Electrical Testing Association.

ii. Dielectric Strength (D.S kV): Table 5 as well as figure 1. (a) and (b) showed the variation of dielectric strength test conducted on the porcelain insulator samples produced. An electrical breakdown occurs when an insulator is subjected to a voltage higher than its designed voltage. This happens when the electric field applied across an insulating substance exceeds in any threshold field for that substance [25]. The dielectric strength of porcelain insulators samples produced were tested and it was observed that sample $\mathrm{B}_{2} \mathrm{P}$ had the highest dielectric strength property of $9.0 \mathrm{kV} / \mathrm{mm}$, followed by sample $A_{1} S$ with $7.9 \mathrm{kV} / \mathrm{mm}$. Samples $A_{2} S$, and $\mathrm{A}_{3} \mathrm{~S}$ had the same dielectric strength of $7.8 \mathrm{kV} / \mathrm{mm}$. Samples $\mathrm{B}_{3} \mathrm{P}, \mathrm{B}_{1} \mathrm{~S}$ and $\mathrm{B}_{3} \mathrm{~S}$ also had the same dielectric strength of $7.7 \mathrm{kV} / \mathrm{mm}$ while sample $\mathrm{B}_{2} \mathrm{~S}$ had $7.6 \mathrm{kV} / \mathrm{mm}$ and Sample $\mathrm{A}_{2} \mathrm{P}$ had the least dielectric strength of $6.0 \mathrm{kV} / \mathrm{mm}$. Nevertheless, sample $\mathrm{B}_{2} \mathrm{P}$ had the highest dielectric strength but all the samples had acceptable dielectric strength value since dielectric strength for shackle insulator is about 6-9kV/mm [26]. The dielectric strength test reiterated sample $\mathrm{A}_{1} \mathrm{~S}$ with $75 \mu \mathrm{m}$ particle size as the most acceptable samples that is required for mechanical and dielectric properties.

Table 5: Insulation Resistance (I.R G $\Omega$ ), and Dielectric Strength (D.S kV) with the samples' compositions sintered at $1200^{\circ} \mathrm{C}$

\begin{tabular}{lcccccc}
\hline & $\mathbf{A}_{\mathbf{1}} \mathbf{S}$ & $\mathbf{A}_{2} \mathbf{S}$ & $\mathbf{A}_{3} \mathbf{S}$ & $\mathbf{B}_{\mathbf{1}} \mathbf{S}$ & $\mathbf{B}_{2} \mathbf{S}$ & $\mathbf{B}_{3} \mathbf{S}$ \\
\hline I.R $(\mathbf{G} \Omega)$ & 1.76 & 1.51 & 1.37 & 1.16 & $\mathbf{1 . 8 4}$ & 1.78 \\
D.S (kV) & $\mathbf{7 . 9}$ & 7.8 & 7.8 & 7.7 & 7.6 & 7.7 \\
& & & & & & \\
\hline
\end{tabular}

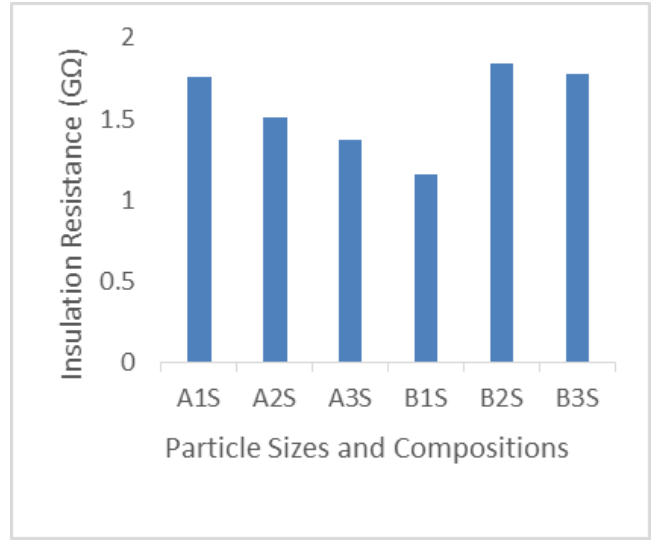

(a)

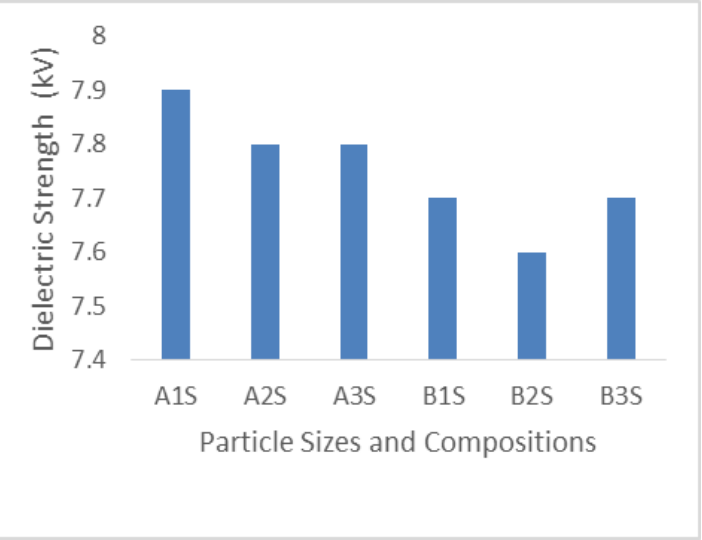

(b)

Figure 1. (a) Insulation Resistance of samples (b) Dielectric Strength of Samples

\subsection{SEM/EDS Analysis of Samples Produced}

The results of the Scanning Electron Microscopy (SEM)/Energy Dispersive X-Ray Spectroscopy (EDS) analysis for all the samples produced are as presented in figures $3-8$. These results show SEM micrograph of the micro structural pattern of the phases of samples produced and fired at 1200 OC, length of $100 \mu \mathrm{m}$ and 
spectra depicting the peaks of the elements present in the samples.

Table 6 Showed the EDS analysis for the elemental composition of the samples and also revealed the actual percentages of the various elements contained in the samples produced. The SEM of the samples were carried out in order to examine the effect of particle sizes on the samples produced are as presented in figures $3-8$. The results revealed that almost all the particles are tightly bonded (sintered) together regardless of the various particle sizes that were used to produce the samples.

The EDS result as presented in Table 6 also proved that all samples produced contain O, Al, and Si which are the major elements required for porcelain formation. The analysis revealed that almost all the samples are free from iron oxide which is detrimental to electrical porcelain insulator due to its conductivity. This analysis gave credence to the result of the electrical resistivity and dielectric strength that were conducted on the samples produced that the samples proved suitable for the production of porcelain insulator.

Table 6: EDS Chemical Analysis of Samples Produced (Wt \%)

\begin{tabular}{ccccccccc}
\hline SAMPLES & $\mathbf{O}$ & $\mathbf{N a}$ & $\mathbf{A l}$ & $\mathbf{S i}$ & $\mathbf{C a}$ & $\mathbf{T i}$ & $\mathbf{F e}$ & $\mathbf{K}$ \\
\hline $\mathbf{A}_{\mathbf{1}} \mathbf{S}$ & 58.36 & 1.22 & 11.19 & 29.23 & - & - & - & - \\
$\mathbf{A}_{2} \mathbf{S}$ & 58.93 & 1.18 & 8.23 & 29.12 & - & - & - & 1.10 \\
$\mathbf{A}_{3} \mathbf{S}$ & 64.20 & 0.96 & 6.56 & 8.34 & - & - & - & 0.24 \\
$\mathbf{B}_{\mathbf{1}} \mathbf{S}$ & 61.30 & 1.13 & 10.33 & 24.86 & 0.34 & 0.58 & - & 1.45 \\
$\mathbf{B}_{2} \mathbf{S}$ & 60.15 & - & 10.78 & 18.25 & - & 0.58 & - & 0.88 \\
$\mathbf{B}_{3} \mathbf{S}$ & 58.34 & 0.43 & 4.44 & 31.79 & 0.29 & - & - & 0.23 \\
\hline
\end{tabular}

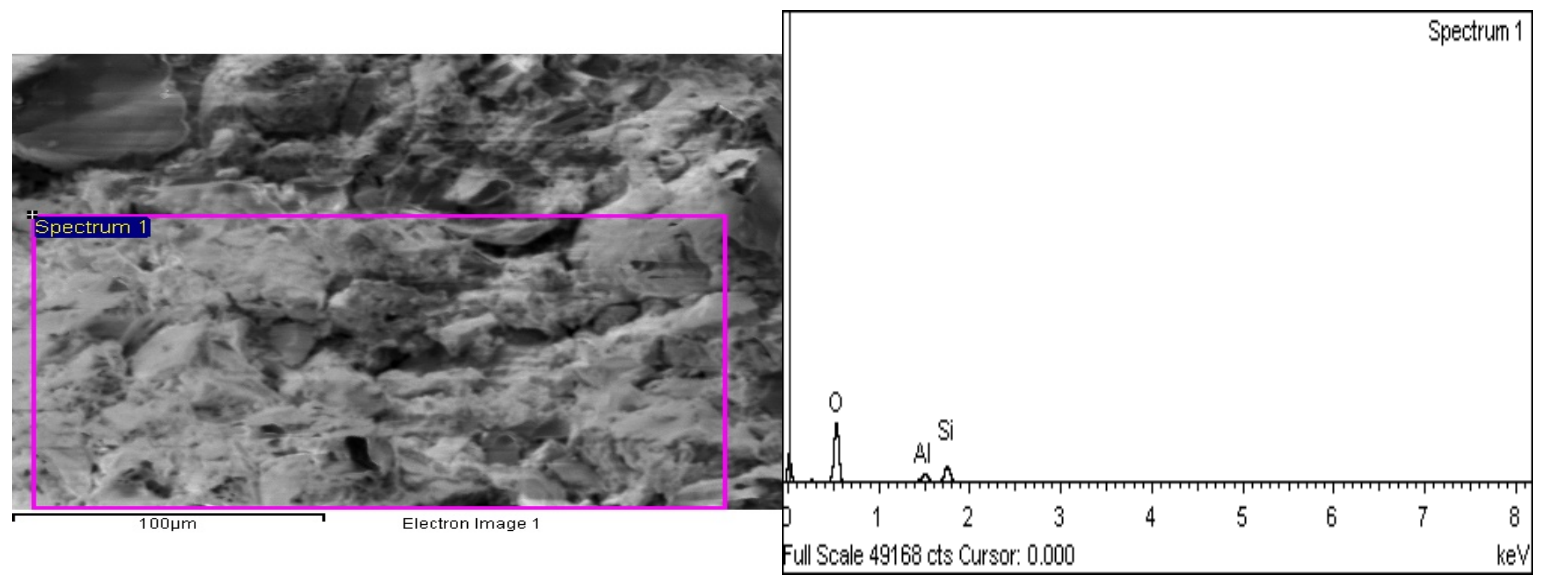

Figure 2: SEM Micrograph of particle size and EDS pattern for Sample $A_{1} S$ 


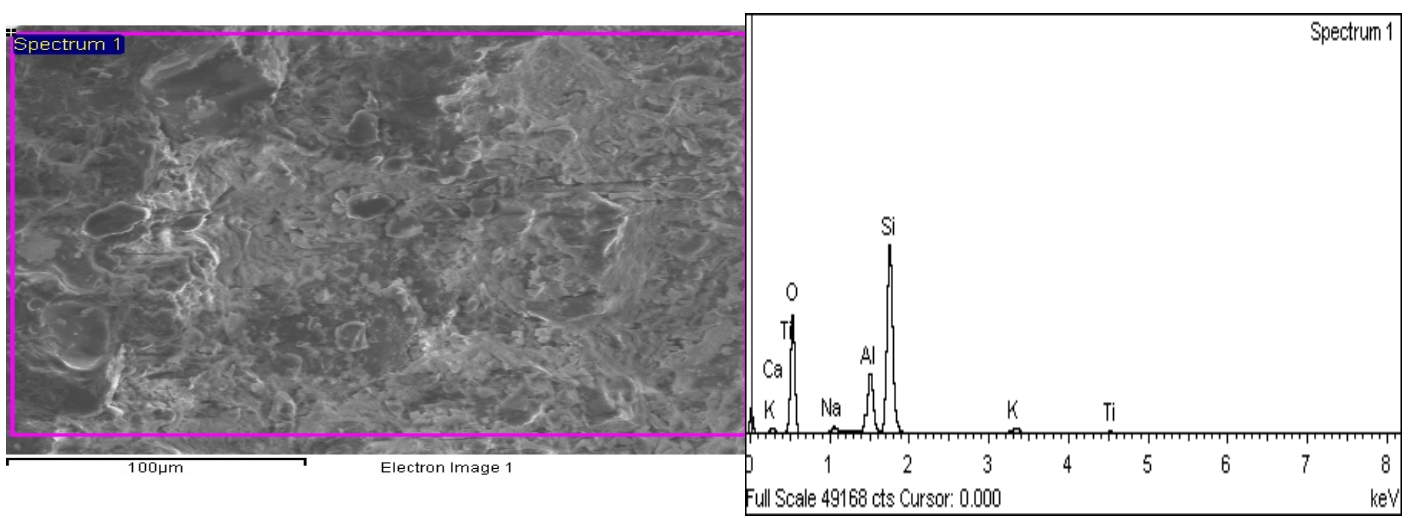

Figure 3: SEM Micrograph and EDS pattern for Sample $\mathrm{A}_{2} \mathrm{~S}$
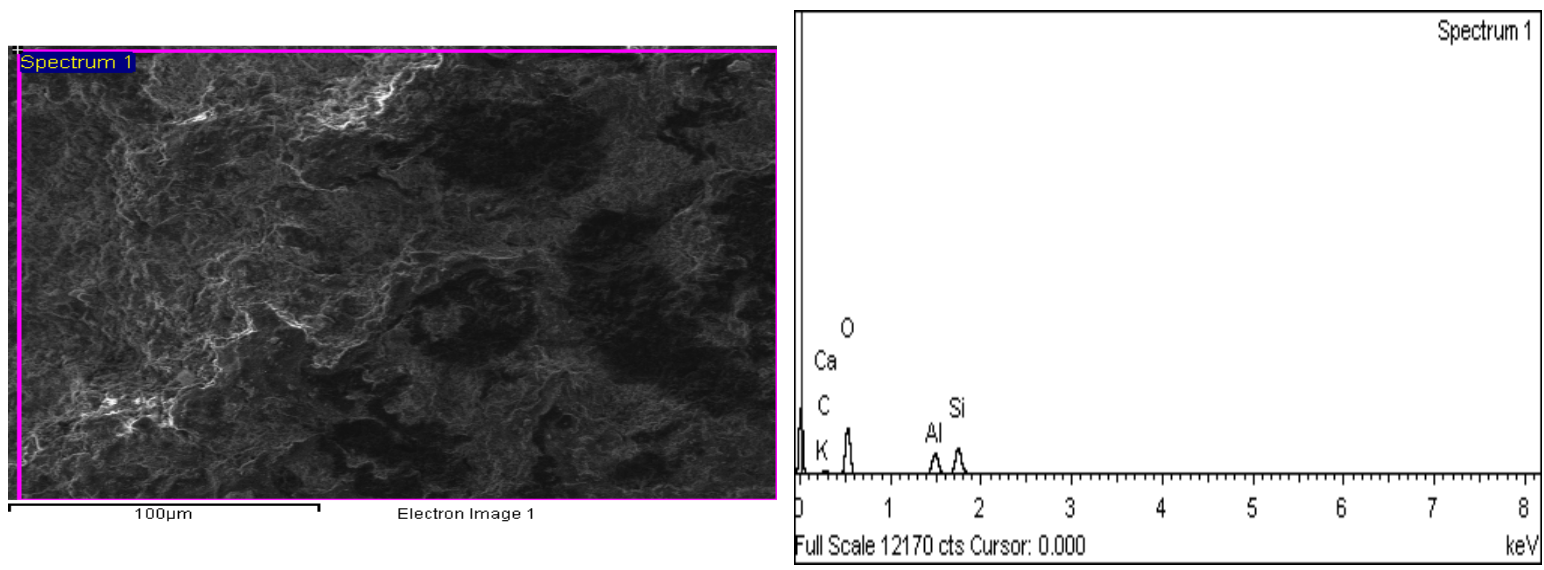

Figure 4: SEM Micrograph and EDS pattern for Sample $A_{3} S$

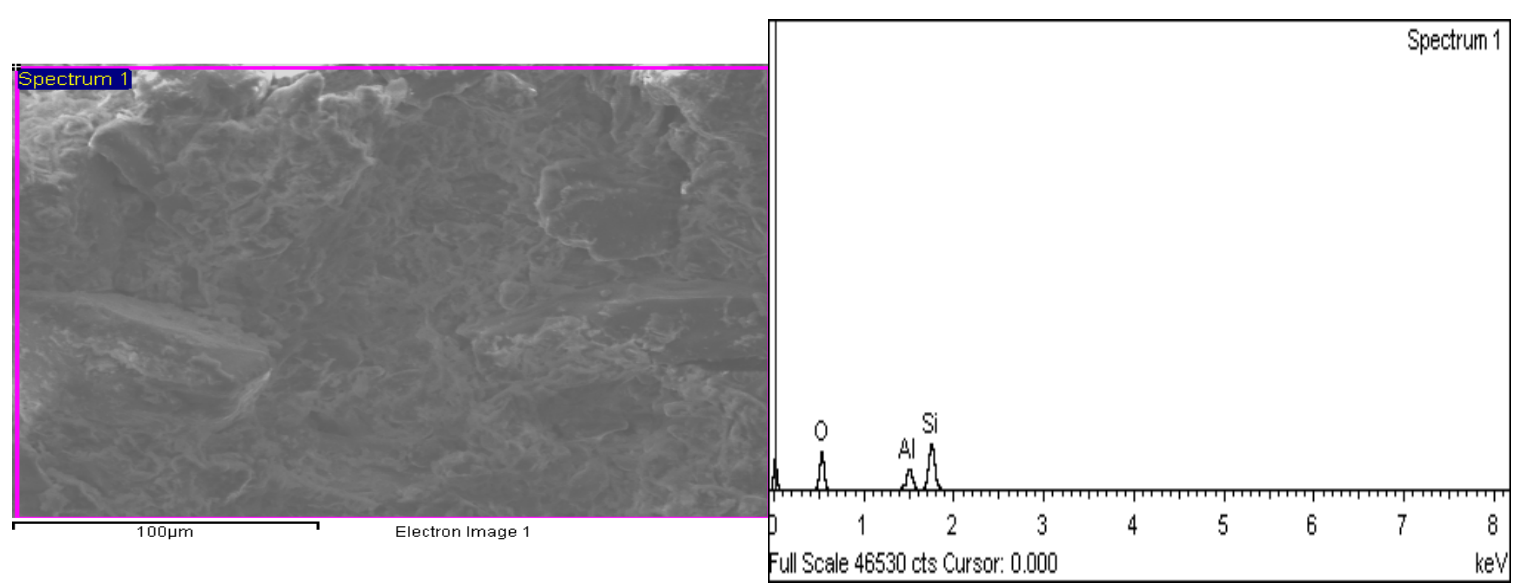

Figure 5: SEM Micrograph and EDS pattern for Sample B1S 

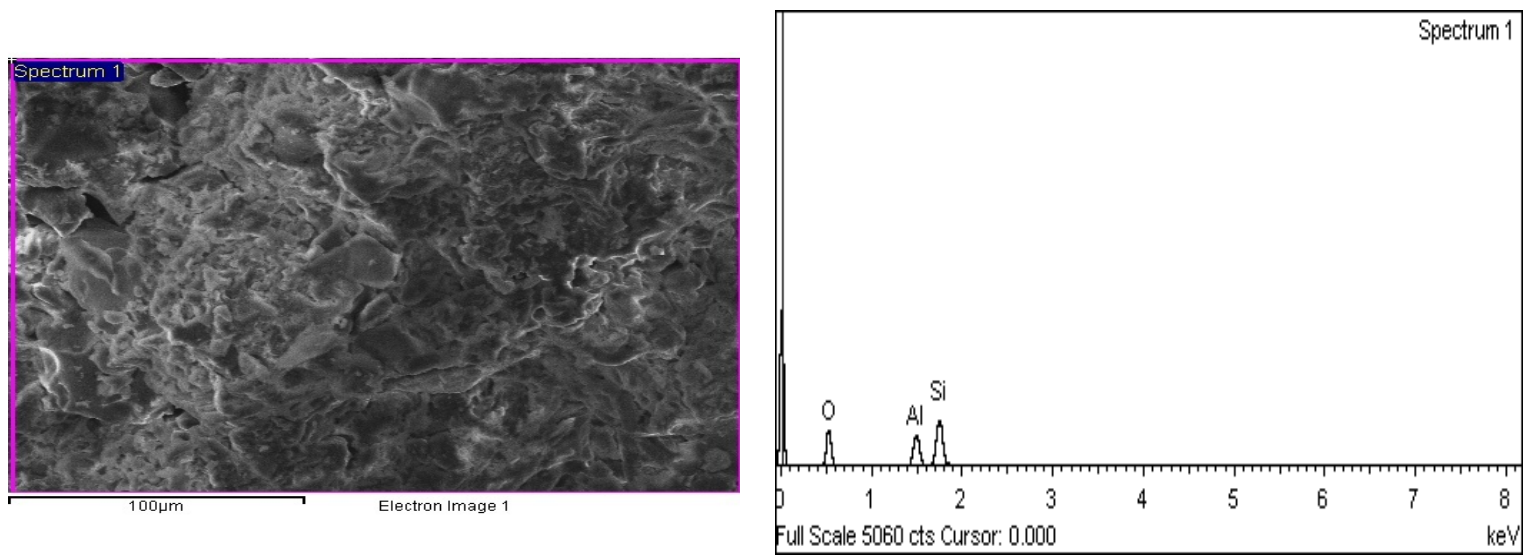

Figure 6: SEM Micrograph and EDS pattern for Sample $\mathrm{B}_{2} \mathrm{~S}$
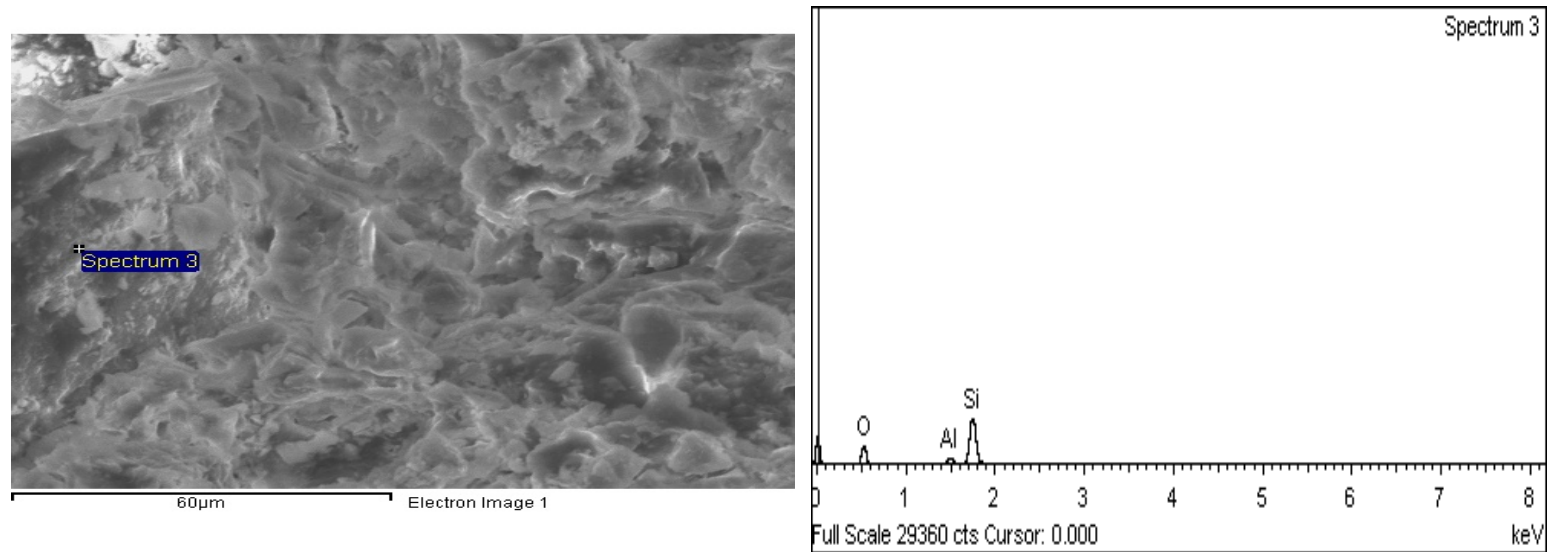

Figure 7: SEM Micrograph and EDS pattern for Sample $B_{3} S$

\section{Conclusion}

The present study investigated the effect of starting particle size of materials that enhance the mechanical and dielectric properties of porcelain insulator. The mix proportion of 30\% wt. kaolin, $15 \% \mathrm{wt}$. clay, $30 \% \mathrm{wt}$. feldspar, and $25 \%$ wt. of quartz at starting particle size powder of $75 \mu \mathrm{m}$ possesses the best mechanical and dielectric strength properties of all the samples. The mix proportion shows the compressive strength of $25.67 \mathrm{kN}$ where the required specification for shackle insulator is $15-16 \mathrm{kN}$. The insulation resistance is $1.76 \mathrm{G} \Omega$ at the injection of $1000 \mathrm{DC}$ voltage while the required minimum insulation resistance is $500 \mathrm{M} \Omega$. It also has dielectric strength of $7.9 \mathrm{kV} / \mathrm{mm}$ at leakage current $>5.0 \mathrm{~mA}$.

However, this study suggests that $150 \mu \mathrm{m}$ particle sizes as a starting powder for production of electrical porcelain Insulator could also be used since mechanical and dielectric strength properties of samples produced with $150 \mu \mathrm{m}$ is also within the recommended value. This would eventually cut down the cost of processing raw materials before usage, and thereby reduce cost of production.

The result obtained from the XRD conducted on the mineralogical composition of the raw materials from Edo State, Nigeria proves its viability for electrical porcelain insulator production for any prospective 
industry to set up her company in Edo state, Nigeria rather than relying on importation of this product. This study recommends raw materials from Edo State suitable for the production of shackle insulator and prospective porcelain insulator industry could establish in this state, considering proximity to available raw materials in order to cut down cost of transporting raw materials.

\section{References}

[1] K. Olaniyan, B. C. McLellan, S. Ogata, and T. Tezuka, "Estimating Residential Electricity Consumption in Nigeria to Support Energy Transitions,” Sustainability, vol. 10, no. 5, p. 1440, May 2018, doi: 10.3390/su10051440.

[2] L. U. Anih, “Indigenous Manufacture and Characterization of Electrical Porcelain Insulator,” Nigerian Journal of Technology, vol. 24, no. 1, pp. 44-50-50, Jan. 2005.

[3] A. O Oladiji, J. O. Borode, B. Adewuyi, and I. Ohijeagbon, "Development of Porcelain Insulators from Locally Sourced Materials,” Journal of Research Information in Civil Engineering, vol. 7, Jan. 2010.

[4] "CHARACTERIZATION OF ELECTRICAL PORCELAIN INSULATORS FROM LOCAL CLAYS.” [Online]. Available: https://www.researchgate.net/publication/306103013_ CHARACTERIZATION_ OF_ELECTRICAL_PORCELAIN_INSULATORS_FROM_LOCAL_CLAYS. [Accessed: 16-Sep-2019].

[5] P. W. Olupot, “Assessment of ceramic raw materials in Uganda for electrical porcelain,” 2006.

[6] A. P. O, O. O. O, and O. T. A, "Electrical Porcelain Production From Selected Kaolin Deposit in South Western Nigeria Using Slip Casting,” International Journal of Materials and Chemistry, vol. 2, no. 3, pp. 86-89, 2012.

[7] A. P. O, O. O. O, and O. T. A, "Electrical Porcelain Production From Selected Kaolin Deposit in South Western Nigeria Using Slip Casting,” International Journal of Materials and Chemistry, vol. 2, no. 3, pp. 86-89, 2012.

[8] F. Singer and S. S. Singer, Industrial Ceramics. Surrey, Britain: Chapman and Hall Ltd., 1963.

[9] O. I. Idowu, "Processing and Uses of Kaolin, A Means of Enhancing Economic Growth in Nigera," Ashakwu, Journal of Ceramics, vol. 1, no. 1, pp. 63-67, 2003.

[10] E. V. Opoku, "Development of local Raw Materials for the Ceramics Industry in Nigeria.,” Ashakwu, Journal of Ceramics, vol. 1, no. 1, pp. 14-17, 2003.

[11] I. B. Kashim, “Developing Local Technology with Abundant Clay Reserves in Nigeria,” Ashakwu, Journal of Ceramics, vol. 1, no. 1, pp. 51-56, 2003.

[12] E. V. Opoku, “Contemporary Development in Ceramic Developments in ceramic Materials: Development of Local Raw Materials for the Ceramic Industry in Nigeria,” Ashakwu, Journal of Ceramics, vol. 1, no. 1, pp. 84-88, 2007.

[13] C. C. Okolo, O. A. Ezechukwu, C. O. Olisakwe, C. E. Ezendokwelu, and C. Umunna, "Characterization of Electrical Porcelain Insulators from Local Clays.," International Journal of Research-GRANTHAALAYAH, vol. 3, no. 1, pp. 26-36, 2015.

[14] P. W. Olupot, S. Jonsson, and J. K. Byaruhanga, "Development and characterisation of triaxial electrical porcelains from Ugandan ceramic minerals,” Ceramics International, vol. 36, no. 4, pp. 1455-1461, May 2010, doi: 10.1016/j.ceramint.2010.02.006.

[15] C08 Committee, “Test Methods for Apparent Porosity, Water Absorption, Apparent Specific Gravity, and Bulk Density of Burned Refractory Brick and Shapes by Boiling Water,” ASTM International. 
[16] "ASTM-C773 | Standard Test Method for Compressive (Crushing) Strength of Fired Whiteware Materials | Document Center, Inc.” [Online]. Available: https://www. document-center.com/ standards/show/ASTM-C773. [Accessed: 30-Aug-2019].

[17] C21 Committee, “Test Methods for Vitrified Ceramic Materials for Electrical Applications,” ASTM International.

[18] G. P. Souza, E. Rambaldi, A. Tucci, L. Esposito, and W. E. Lee, "Microstructural Variation in Porcelain Stoneware as a Function of Flux System,” Journal of the American Ceramic Society, vol. 87, no. 10, pp. 1959-1966, 2004, doi: 10.1111/j.1151-2916.2004.tb06347.x.

[19] F. Sahnoune, M. Chegaar, N. Saheb, P. Goeuriot, and F. Valdivieso, “Algerian kaolinite used for mullite formation,” Applied Clay Science, vol. 38, no. 3, pp. 304-310, Feb. 2008, doi: 10.1016/j.clay.2007.04.013.

[20] Naikui Gao, Hengkun Xie, and Zongren Peng, "Effect of water absorption on dielectric properties of EPDM/Al(OH)/sub 3/ composites," in Proceedings of the 6th International Conference on Properties and Applications of Dielectric Materials (Cat. No.00CH36347), 2000, vol. 2, pp. 905-907 vol.2, doi: 10.1109/ICPADM.2000.876376.

[21] J. A. Glasscock et al., "The effect of forming stresses on the sintering of ultra-fine $\mathrm{Ce} 0.9 \mathrm{Gd} 0.1 \mathrm{O} 2-\delta$ powders,” Journal of the European Ceramic Society, vol. 33, no. 7, pp. 1289-1296, Jul. 2013, doi: 10.1016/j.jeurceramsoc.2012.12.015.

[22] A. Merga, H. C. A. Murthy, E. Amare, K. Ahmed, and E. Bekele, "Fabrication of electrical porcelain insulator from ceramic raw materials of Oromia region, Ethiopia,” Heliyon, vol. 5, no. 8, p. e02327, Aug. 2019, doi: 10.1016/j.heliyon.2019.e02327.

[23] S. Kasrani, A. Harabi, S.-E. Barama, L. Foughali, M. T. Benhassine, and D. M. Aldhayan, "Sintering and dielectric properties of a technical porcelain prepared from economical natural raw materials," Cerâmica, vol. 62, no. 364, pp. 405-412, Dec. 2016, doi: 10.1590/0366-69132016623641994.

[24] G. M. Moses and E. Park, "Ceramic Raw Materials in Tanzania - Structure and Properties for Electrical Insulation Application,” International Journal of Engineering Research \& Technology (IJERT), vol. 3, no. 10, 2014.

[25] P. I. Obi and J. P. I. Iloh, "Various Types of Insulators Used in Power System for Safe Operations of the Transmission Lines,” International Journal of Innovative Engineering, Technology and Science (IJIEST), vol. 1, no. 1, 2016.

[26] S. Nasejje and O. K. Sam, "Dependency of Dielectric Strength of Kaolin on Processing Method," Journal of Scientific Research \& Reports (JSSR), vol. 4, no. 4, 2015. 


\section{Appendix}

A1. Prototype of Shackle Insulators produced from this study

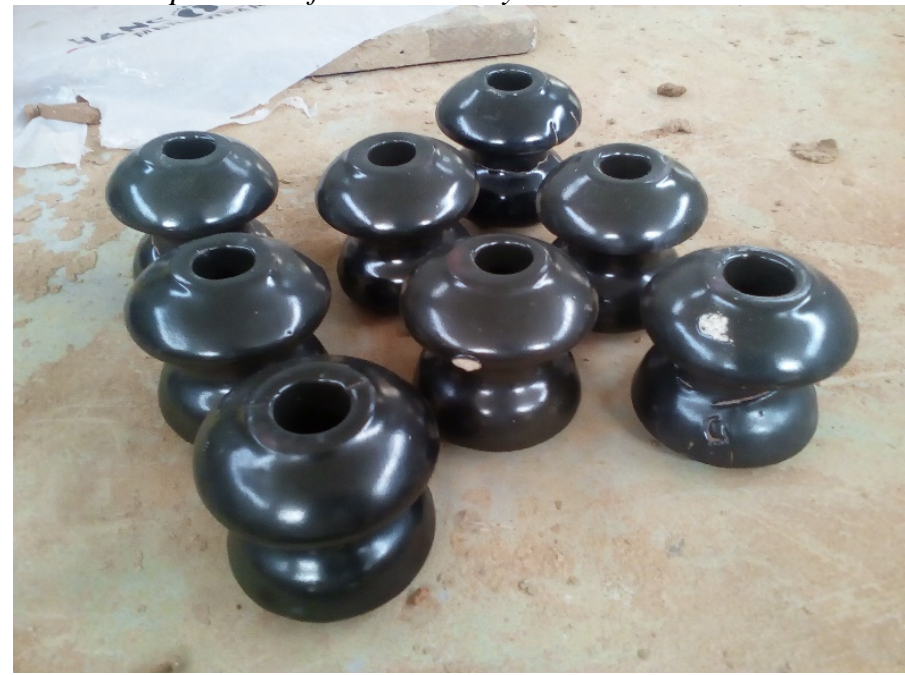

\section{Author(s) Profile}

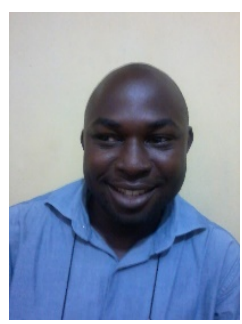

Ologunwa Temitope P. (Ph.D) had his B.Tech and M.Tech degrees in Industrial Design (Ceramics Option). He holds $\mathrm{PhD}$ degree in Ceramics. He is currently a Lecturer I at the Department of Industrial Design, School of Environmental Technology, Federal University of Technology, Akure, Nigeria. He lectures both undergraduate and postgraduate students in Ceramics courses at different levels for the past seven years. He has presented research papers in conference and published both in national and international peer reviewed journals. He is also a member of Ceramic Researchers' Association of Nigeria, (CeRAN).

How to cite this paper: Temitope Peter, Ologunwa. "Process and Development of Electrical Porcelain Insulator Using Edo State, Nigerian Raw Materials ", International Journal of Engineering and Manufacturing(IJEM), Vol.10, No.3, pp.43-55, 2020. DOI: 10.5815/ijem.2020.03.04 